\title{
Host Cognition and Parasitism in Birds: A Review of the Main Mechanisms
}

\author{
Simon Ducatez ${ }^{1,2 *}$, Louis Lefebvre ${ }^{1,2}$, Ferran Sayol,3, Jean-Nicolas Audet ${ }^{5}$ and \\ Daniel Sol 2,6
}

1 Department of Biology, McGill University, Montréal, QC, Canada, ${ }^{2}$ Centre de Recerca Ecologica i Aplicacions Forestals (CREAF), Universitat Autonoma de Barcelona, Barcelona, Spain, ${ }^{3}$ Department of Biological and Environmental Sciences, University of Gothenburg, Gothenburg, Sweden, ${ }^{4}$ Gothenburg Global Biodiversity Centre, Gothenburg, Sweden, ${ }^{5}$ Field Research Center, The Rockefeller University, New York, NY, United States, ${ }^{6}$ Consejo Superior de Investigaciones Cientificas (CSIC), Barcelona, Spain

\section{OPEN ACCESS}

Edited by:

Blandine Françoise Doligez, Centre National de la Recherche

Scientifique (CNRS), France

Reviewed by:

Dale Clayton

The University of Utah, United States Shelley Adamo,

Dalhousie University, Canada

*Correspondence:

Simon Ducatez

simon.ducatez@gmail.com

Specialty section:

This article was submitted to Behavioral and Evolutionary Ecology,

a section of the journal

Frontiers in Ecology and Evolution

Received: 23 September 2019

Accepted: 30 March 2020

Published: 23 April 2020

Citation:

Ducatez S, Lefebvre L, Sayol F, Audet J-N and Sol D (2020) Host Cognition and Parasitism in Birds: A Review of the Main Mechanisms. Front. Ecol. Evol. 8:102. doi: 10.3389/fevo.2020.00102
Parasites can have important detrimental effects on host fitness, thereby influencing their ecology and evolution. Hosts can, in turn, exert strong selective pressures on their parasites, affecting eco-evolutionary dynamics. Although the reciprocal pressures that hosts and parasites exert on each other have long been recognized, the mechanisms are insufficiently understood. Here, we discuss the role of host cognition in host-parasite eco-evolutionary dynamics. Theoretical advances have acknowledged the importance of behavior in shaping these dynamics, but how and why host cognition should affect and/or be affected by parasites is less clear. We propose three scenarios that may create causal and non-causal links between cognition and the richness, prevalence and intensity of parasites. First, host cognition may change the probability of exposure to parasites, either increasing (e.g., altering the relationship with the environment via innovative behaviors) or decreasing (e.g., influencing decision-making to avoid infected conspecifics) exposure. Second, parasites may change host cognitive performance, for example, by reducing host condition. Finally, host cognition and parasites can be associated via common causal factors (e.g., shared molecular pathways), energetic constraints generating trade-offs between cognition and immunocompetence, or trait co-evolution with life history, ecological, or social strategies. The existence of such a variety of non-mutually exclusive mechanisms suggests that host cognition has a great potential to affect and be affected by parasites. However, it also implies that progress in understanding these effects will only be possible if we distinguish between causal and non-causal links.

Keywords: behavioral plasticity, cognition, expensive tissue hypothesis, exposure hypothesis, immune traits, infection costs, parasite avoidance, pathogen

\section{INTRODUCTION}

Cognition includes all ways in which animals collect information, process, retain and decide to act on it (Shettleworth, 2001, 2010). Because these cognitive functions deeply affect how animals interact with their environment, the study of cognition has long been recognized as central to understand the ecology and evolution of animals. Thus, cognition has been linked to a variety 
of key eco-evolutionary processes such as range expansions, niche shifts, population dynamics, and adaptive divergence (Sol et al., 2005; Ducatez et al., 2015; Sayol et al., 2016, 2019; Fristoe et al., 2017; Riotte-Lambert et al., 2017). Although cognition is also thought to be essential to eco-evolutionary dynamics in hostparasite systems, evidence remains scarce (but see, e.g., Ader et al., 2006; Gómez-Moracho et al., 2017).

Here, we argue that a major obstacle to understanding how host cognition affects and is affected by parasites has been the lack of a general theoretical framework for the different scenarios under which associations between parasites and cognition are expected. Developing such a framework has been particularly challenging because the causality of associations between parasites and cognition takes a variety of forms and can even change direction depending on the scenario, making it difficult to make unique, falsifiable predictions. Cognition can be affected by parasites: for example, most infections by pathogens can directly impair animal cognitive performance (Binning et al., 2018). However, cognition can also affect parasitism, e.g., by allowing a host to learn to avoid being exposed to pathogens (Zhang et al., 2005). Another mechanism through which cognition may influence parasitism is by promoting innovative behavior, which may increase (or decrease) exposure to parasites (Garamszegi et al., 2007). Although this predicts higher parasite loads, a long exposure to parasites may select for enhanced immune systems that reduce the intensity of infections. An association between parasites and cognition may even arise with no need for direct causal mechanisms. Cognition and parasite defenses may be associated as a result of indirect or common causes because they are co-selected in organisms with particular lifestyles (e.g., long-lived or generalist species, Overington et al., 2011; Ducatez et al., 2015; Sol et al., 2016) or because similar molecular pathways affect the two functions (Bilbo and Schwarz, 2012; Grindstaff, 2016). The main aim of our article is to organize the mechanisms expected to create parasite-host cognition associations in a common framework, hoping to build bridges between parasitologists, immunologists, behavioral ecologists and psychologists. Our ultimate goal is to provide a more solid basis for future investigations on the role of parasites in the evolution of cognition, and, conversely, the role of host cognition in the evolution of parasites.

To better understand the impact of parasites on ecoevolutionary dynamics, parasitologists have investigated patterns of variation in parasitism across a wide range of organisms (Poulin and Morand, 2000; Nunn et al., 2003; Lindenfors et al., 2007; Arriero and Møller, 2008; Bordes et al., 2009; Kamiya et al., 2014; Poulin, 2014). Two main theoretical frameworks determine the processes responsible for the main patterns of variation (Poulin and Morand, 2000), and can also provide insights to predict eventual associations between host cognition and parasitism. First, by considering individual hosts as "islands" that can be colonized by parasites, island biogeography theory (MacArthur and Wilson, 1967) offers explanations on, among other patterns, the increase in parasite species richness with host size and host geographic range (Kamiya et al., 2014). Second, by deriving the "basic reproductive rate" $\left(R_{0}\right.$, defined as the average number of new cases of infections that arise from one infectious host), epidemiology models also provide clear predictions on the way host traits can affect parasitism (Anderson and May, 1979; May and Anderson, 1979). These models predict, for example that host population density, by affecting the probability of encounter with parasites, should increase parasite richness, a prediction supported by several empirical studies (e.g., Morand and Poulin, 1998; Arneberg, 2002; Kamiya et al., 2014). These two main theories suggest that host cognition can affect parasitism if it determines the host probability of exposure to parasites, or the probability of parasites' transfer among hosts. Clearly, the probability of transfer will also be determined by the host's (in)ability to eliminate the parasite, and thus by its defense mechanisms. These simple models are however complicated by the fact that parasite characteristics per se also play a central role determining parasitism and the interaction between cognition and parasitism, while the metrics used to measure parasitism (prevalence, infection intensity, species richness, etc.) also matter. Although still rarely tested, we discuss in the next paragraph how parasite characteristics may affect the association between parasites and their host's cognition, before focusing our review mostly on the host's perspective.

The mode of parasite transmission is especially likely to affect the interaction between cognition and parasitism. Whether the parasites are transmitted via direct contact with conspecifics (e.g., lice), via contact with the feces of conspecifics (e.g., coccidian parasites) or via a vector (e.g., mosquitoes for malaria) will determine whether and how host cognitive activities affect parasite transmission: for example, social learning may increase the level of social interactions, in turn favoring the exposure to socially transmitted parasites (McCabe et al., 2014; Kavaliers and Choleris, 2018). Host specificity will similarly be an important determinant of whether cognitive activities involving direct or indirect (e.g., via a vector, the predation of another species, or contact with feces) interactions with other species (e.g., foraging innovations and inter-specific social learning) can have an impact on parasitism. The virulence of the parasites is also likely to affect the association between cognition and parasitism, e.g., because a highly virulent parasite will globally decrease the performances of an individual, including its cognitive performance, whereas a less virulent one may not have any detectable effect. A highly virulent parasite may also trigger strong evolutionary responses by the host, including by devising new defenses allowing to limit the parasite effects, or avoid exposure (e.g., via associative learning; Zhang et al., 2005). The characteristics of the parasite's cycle may also be important. Especially, parasites may manipulate their host cognition if they need to be exposed to specific conditions, or to other hosts, to complete their cycle (as they manipulate their host's behavior; see Moore, 2002). Finally, considering metrics of prevalence, infection intensity or parasite species richness is likely to provide different information. For example, the prevalence of a parasite is mostly affected by the probability of encounter between a host and a parasite, whereas the richness of parasite species 
recorded on a given species is likely to be driven by the diversity of biotic and abiotic conditions encountered by the host, and by parasite specificity and diversification dynamics (Poulin, 2006).

We organize the review in three sections. In the first section, we briefly review empirical evidence for associations between cognition and parasites, distinguishing studies conducted within and across species. Although laboratory model organisms, such as rats (Rattus norvegicus) or Caenorhabditis elegans, provide key information with regards to the cellular and molecular mechanisms that can link cognition and defense against parasitism (e.g., see Anderson and McMullan, 2018; see also Ader et al., 2006), they are less informative with regards to the eco-evolutionary history of parasite/cognition associations. Studies in wild birds instead have led to fundamental discoveries in our understanding of natural host-parasite systems (see Clayton and Moore, 1997; Poulin, 2006), and have also been at the forefront of the recent advances in the ecology and evolution of cognition (e.g., Lefebvre et al., 1997; Sol et al., 2005, 2016; Morand-Ferron and Quinn, 2011; Cole et al., 2012; Cauchard et al., 2013; Morand-Ferron et al., 2016; Olkowicz et al., 2016; Rutz et al., 2016; Sayol et al., 2016, 2018; ten Cate and Healy, 2017; Ashton et al., 2018; Audet et al., 2018; Branch et al., 2019; Sonnenberg et al., 2019). We thus conducted a thorough review of the bird literature, mostly focusing on studies of wild birds, a relevant context to consider the eco-evolutionary dynamics of parasites and their hosts' cognition.

Several studies in insects (especially bees) have empirically demonstrated the effects of parasite infection on cognition (e.g., see Gegear et al., 2006; Mobley and Gegear, 2018). This research has been thoroughly reviewed and discussed recently, and we thus refer the reader to Gómez-Moracho et al. (2017) for more information. Research on other vertebrate taxa, including mammals (particularly primates and rodents, e.g., see McCabe et al., 2014; Kavaliers and Choleris, 2018) and fish (e.g., Kotrschal et al., 2016; Binning et al., 2018), have also been conducted, providing insights into the mechanisms that may also be at play in birds, and we discuss key results stemming from studies on other taxa when relevant. Our literature review (summarized in Table 1) shows that the association between host cognition and the richness, prevalence and intensity of parasites has rarely been investigated in wild birds. It also highlights that patterns of covariation can largely vary depending on the biology of the host and parasites. Parasites' mode of transmission and host specificity are, for example, key traits determining how cognition can affect host parasitism.

In the second section, we provide a framework explaining the observed associations between cognition and parasites (summarized in Figure 1). Specifically, we identify three scenarios under which an association between cognition and parasites is expected: cognition can causally affect parasitism, parasitism can causally affect cognition, or the association between cognition and parasites may not be causal, but instead be due to a third co-factor. For each scenario, we discuss the underlying mechanisms and provide examples (see also Table 2).
In the third section of this article, we identify gaps in knowledge on the role of cognition in host-parasite eco-evolutionary dynamics and discuss methodological challenges to guide future research.

\section{COGNITION AND PARASITES IN THE WILD}

\section{Within-Species Analyses}

Parasites have long been known to affect and be affected by host behavior. In a pioneering study, Wilson et al. (1993) found, for instance, that pumpkinseed sunfish (Lepomis gibbosus) caught in traps - perhaps reflecting their "bolder" or more "exploratory" personalities - had different levels of parasite infection than the average of the population. For one parasite (Neascus sp.), the load was higher in trapped fish, whereas the opposite pattern was detected for a second parasite, Posthodiplostomum minimum. This work demonstrated an association between parasites and host behavior, but mostly raised key questions with regards to the causality of the association, especially since it appeared to vary according to the parasite.

While the link between behavior and parasites is now welldocumented, including in wild birds (e.g., see Barber and Dingemanse, 2010; Kortet et al., 2010; Poulin, 2013; Lopes, 2017; Sarabian et al., 2018; Sih et al., 2018), less effort has been devoted to identify the cognitive processes involved. Birds illustrate this point quite well (see Table 1). At the intra-specific level, we are aware of only five studies testing for associations between cognitive traits and either parasites or immune traits. In a study on house sparrows (Passer domesticus), birds that were faster at solving a problem also tended to have fewer coccidian parasites (parasites that infect the digestive tracts and are transmitted via contact with the feces of infected individuals; Bókony et al., 2014). However, this pattern only emerged in one of the four tasks measured, the one that was the most difficult to solve (only $22.8 \%$ of the tested birds solved it, compared to 72.4 to $83.3 \%$ for the other tasks). The pattern might reflect a negative effect of parasite infection on cognitive performance, although the observational nature of the study does not allow one to infer causality. In another study, Dunn et al. (2011) found a sex-dependent association between problem-solving performance and malaria prevalence in wild great tits (Parus major). Infected males showed an increased performance, whereas the reverse was true for females. Although the causality of these patterns could again not be inferred given the correlative nature of the study, the authors suggested that the increased performance of infected males may be explained by the higher exposure to parasites of problemsolvers, resulting from their more diverse foraging habits. Instead, the lower performance of infected females could be explained by a negative effect of malaria on their cognitive abilities, similar to the negative effect of coccidian parasites on sparrow cognition (Bókony et al., 2014). However, an experimental study did not confirm the latter interpretation. Cauchard et al. (2016) found that wild female great tits treated with an anti-malaria drug did not outperform control birds in a problem-solving task. Malaria infection thus did not seem to affect problem-solving 
TABLE 1 | Patterns of covariation between cognitive traits and parasitism or host defense in wild birds from studies considering intraspecific or interspecific variation.

\begin{tabular}{|c|c|c|c|c|c|c|c|c|c|}
\hline Host & Parasite & $\begin{array}{l}\text { Parasitism } \\
\text { measure }\end{array}$ & Transmission mode & Location & Cognition measure & Relationship & Causal relationship & $\begin{array}{l}\text { Host } \\
\text { defense }\end{array}$ & References \\
\hline \multicolumn{10}{|c|}{ Intraspecific level studies } \\
\hline \multirow{4}{*}{$\begin{array}{l}\text { House sparrow } \\
\text { (Passer } \\
\text { domesticus) }\end{array}$} & Coccidia & Load & Contact with feces & Hungary & Problem solving 1 & - & Unknown & & Bókony et al. (2014) \\
\hline & Coccidia & Load & Contact with feces & Hungary & Problem solving 2 & 0 & Unknown & & Bókony et al. (2014) \\
\hline & Coccidia & Load & Contact with feces & Hungary & Problem solving 3 & 0 & Unknown & & Bókony et al. (2014) \\
\hline & Coccidia & Load & Contact with feces & Hungary & Problem solving 4 & 0 & Unknown & & Bókony et al. (2014) \\
\hline \multirow[t]{2}{*}{$\begin{array}{l}\text { Great tit (Parus } \\
\text { major) }\end{array}$} & Malaria & Prevalence & Arthropod vector & Sweden & Problem solving & $\begin{array}{l}\text { - in males, } \\
+ \text { in females }\end{array}$ & Unknown & & Dunn et al. (2011) \\
\hline & Malaria & - & Arthropod vector & Sweden & Problem solving & 0 & Experimental & $\begin{array}{l}\text { Anti-malaria } \\
\text { treatment }\end{array}$ & Cauchard et al. (2016) \\
\hline \multirow{4}{*}{$\begin{array}{l}\text { Carib grackle } \\
\text { (Quiscalus lugubris) }\end{array}$} & & & & Barbados & Problem solving & - & Unknown & $\mathrm{PHA}$ & Ducatez et al. (2019) \\
\hline & & & & Barbados & Associative learning & + & Unknown & $\mathrm{PHA}$ & Ducatez et al. (2019) \\
\hline & & & & Barbados & Reversal learning & + & Unknown & PHA & Ducatez et al. (2019) \\
\hline & & & & Barbados & Detour reaching & + & Unknown & $\mathrm{PHA}$ & Ducatez et al. (2019) \\
\hline \multirow{4}{*}{$\begin{array}{l}\text { Barbados bullfinch } \\
\text { (Loxigilla } \\
\text { barbadensis) }\end{array}$} & & & & Barbados & Problem solving & 0 & Unknown & PHA & Audet et al. (2016) \\
\hline & & & & Barbados & Associative learning & 0 & Unknown & PHA & Audet et al. (2016) \\
\hline & & & & Barbados & Reversal learning & 0 & Unknown & $\mathrm{PHA}$ & Audet et al. (2016) \\
\hline & & & & Barbados & Detour reaching & 0 & Unknown & PHA & Audet et al. (2016) \\
\hline \multicolumn{10}{|c|}{ Inter-species level studies } \\
\hline 45 Bird species & Haematozoa & Prevalence & Arthropod vector & Palearctic & Foraging innovation rate & + & Unknown & & Garamszegi et al. (2007) \\
\hline 55 Bird species & Egg bacteria & Load & Direct contact? & Palearctic & Foraging innovation rate & + & Unknown & & Soler et al. (2012) \\
\hline 107 Bird families & Amblyceran lice & Richness & Direct contact & Global & Foraging innovation rate & + & Unknown & & Vas et al. (2011) \\
\hline 107 Bird families & Ischnoceran lice & Richness & Direct contact & Global & Foraging innovation rate & & & & Vas et al. (2011) \\
\hline 107 Bird families & Amblyceran lice & Richness & Direct contact & Global & Brain size & + & Unknown & & Vas et al. (2011) \\
\hline 107 Bird families & Ischnoceran lice & Richness & Direct contact & Global & Brain size & 0 & Unknown & & Vas et al. (2011) \\
\hline 59 Bird species & & & & Palearctic & Brain size & + in males & Unknown & $\begin{array}{l}\text { Bursa of } \\
\text { Fabricius } \\
\text { size }\end{array}$ & Møller et al. (2005) \\
\hline 127 Bird species & & & & Palearctic & Brain size & + in males & Unknown & Spleen size & Møller et al. (2005) \\
\hline 77 Bird species & & & & Palearctic & Foraging innovation rate & + & Unknown & $\begin{array}{l}\text { Bursa of } \\
\text { Fabricius } \\
\text { size }\end{array}$ & Garamszegi et al. (2007) \\
\hline 97 Bird species & & & & Palearctic & Foraging innovation rate & + & Unknown & Spleen size & Garamszegi et al. (2007) \\
\hline 48 Bird species & & & & Palearctic & Foraging innovation rate & + & Unknown & Thymus size & Garamszegi et al. (2007) \\
\hline
\end{tabular}




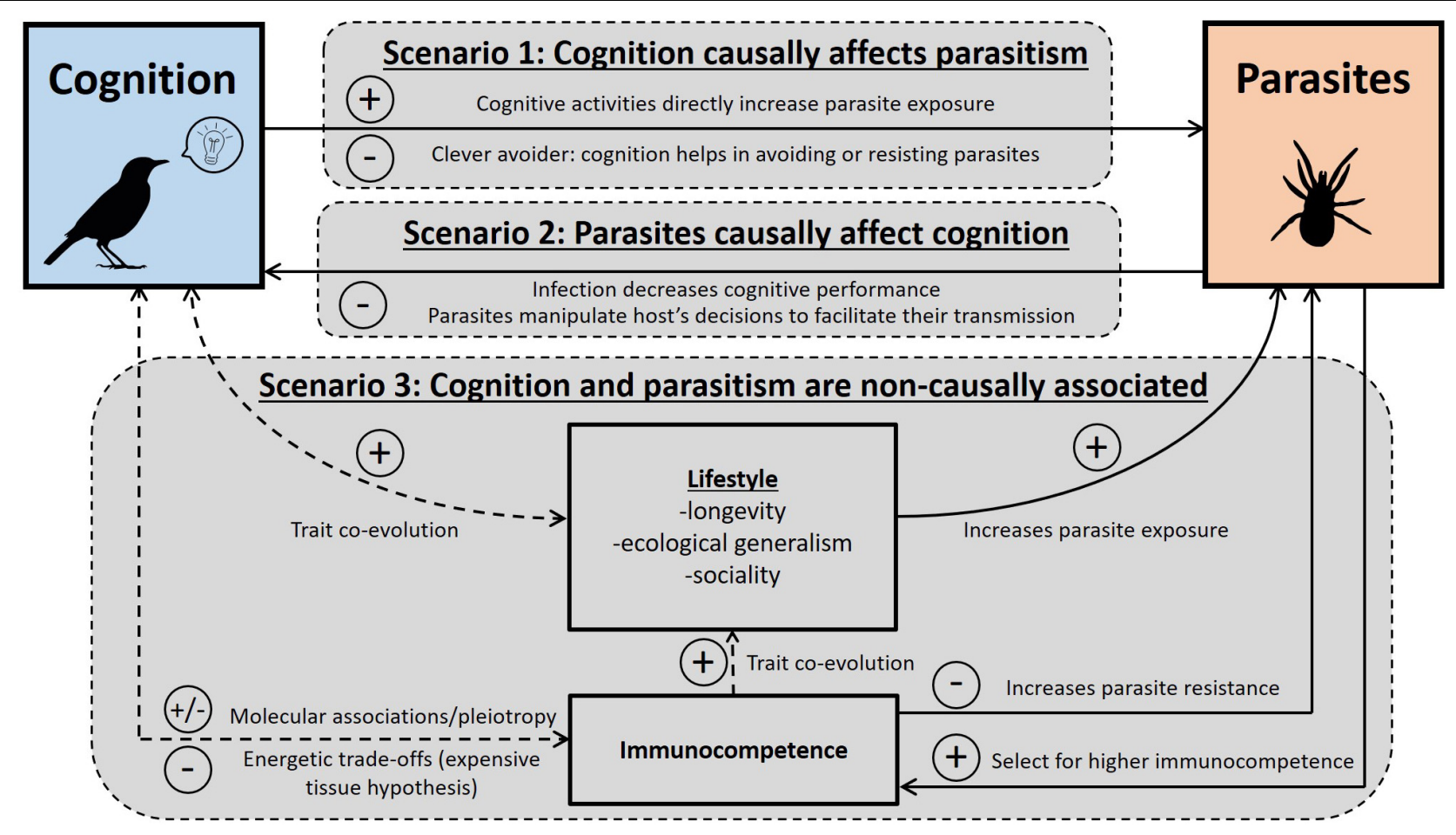

FIGURE 1 | Diagram presenting the different scenarios predicting associations between host cognitive traits and parasitism. Each of the three scenarios involves one or more different mechanisms. Solid arrow: causal association. Dashed arrow: non-causal association resulting from constraints or trait co-evolution. + : positive associations expected; - : negative associations expected; \pm : both positive and negative associations expected.

performance in this system, although problem-solving was tested shortly after the drug injection, and long-term effects of infection could thus not be discarded (Cauchard et al., 2016).

Still at the intra-specific level, two studies tested for associations between cognitive performance and response to PHA, an immunoecological technique assessing general innate immunity, and to a lesser extent adaptive immunity (Martin et al., 2006). Artificial activation of immune responses, though very different from actual infections with pathogens, can be particularly informative to measure the covariation between traits affecting parasite resistance (i.e., immune traits) and cognitive performances. In Carib grackles (Quiscalus lugubris) from Barbados, individuals' response to PHA was associated with their performance in different cognitive tasks; PHA response was higher in grackles that were slow but accurate at problem-solving, associative learning and reversal learning tasks, and in grackles with better detour-reaching performance (Ducatez et al., 2019). The higher PHA response of slow-paced species detected by Martin et al. (2011) is in line with this result, suggesting that immunocompetence and cognition may co-evolve within a given lifestyle. However, the causality of the association remains untested, and other immune traits should be considered, as general immunocompetence is the result of a diversity of immune traits. In contrast, in a similar study on Barbados bullfinches (Loxigilla barbadensis), variation in performance at similar cognitive tests was not associated with variation in response to PHA (Audet et al., 2016).
Despite the lack of association at the individual level, this last study detected co-variation at the population level: individuals from urban areas displayed both enhanced problem-solving performances and higher PHA responses as compared to their rural conspecifics. This result suggests that immunocompetence and cognition may respond to similar pressures (here, urbanization), even if they are not associated directly.

Together, these studies lead to the following conclusions. First, the results appear, at first sight, largely inconsistent from one study to another, as increased parasitism can either be associated with increased or decreased cognitive performances, or can be unrelated to cognition. Similarly, the association between a proxy of immunocompetence and cognitive performance was significant in one, but not in the other tested species. Second, except for one study, all analyses so far are correlative, making it difficult to determine the causality of the observed patterns. Third, even though several studies followed recent recommendations to characterize individual cognitive skills by measuring performance at a diversity of psychometric measurements (Rowe and Healy, 2014; Thornton et al., 2014), all of these studies focused on either one measure of immunocompetence or one type of parasite. Immune traits are labile and depend on past infection history and host-parasite co-evolution. In addition, different parasites differently affect their hosts. Future studies should thus favor experiments manipulating or controlling parasite infection 
TABLE 2 | Main mechanisms predicting associations between parasitism and cognition, with examples from the literature and analyses/experiments required to provide more evidence for the different mechanisms. main difficulty

1.1 Cognitive activities increase McCabe et al. (2014) in primates; some correlative evidence in birds, but no test of causality (e.g Garamszegi et al., 2007)

1.2 Cognitive abilities help to avoid or respond to parasites

Zhang et al. (2005) in C. elegans; in birds, examples of innovative anti-parasite behaviors

2.1 Cognitive cost of parasite nfection

2.2 Parasites manipulate their host cognition

3.1 Cognition is associated with lifest Social intelligence and social parasites

Ecological generalism cognition, and parasite exposure

Life history, cognition, and parasite exposure

3.2 Brain/immunocompetence trade-offs: the expensive tissue hypothesis

3.3 Molecular associations and Pleiotropic effects on immune traits and cognition in pleiotropy immune response on cognitive performance in zebra other than birds (e.g., arthropods; Moore, 2002); unclear how cognition is affected cognition and life history (e.g., Sol et al., 2016) and between life history and parasitism (e.g., Poulin and Morand, 2000) brain size also reduced innate immune response

humans (MacMurray et al. 2014; Napolioni et a ", 2014), no studies in wild animals

\section{Future development} high parasitism, or determine the role of cognitive mechanisms in the finch (e.g., Grindstaff et al., 2012)

Numerous examples of behavioral manipulations in taxa

Experimental infection; e.g., infect a host and measure its cognition in

Kotrschal et al. (2016) in guppies - artificial selection on
Comparative analysis: assess the causality of associations between cognitive traits and parasites which transmission mode is related to the cognitive activity considered using path analyses; e.g., birds foraging innovation rate and helminth species richness

Provide field and experimental evidence of parasite removal/avoidance using cognition; e.g., test whether birds can learn to avoid an area with emergence of behavioral innovations limiting parasite effects

Experimental manipulation of parasitism; e.g., infect or disinfect hosts with malaria or other parasites and measure the consequence on their cognition context that affects the parasite's transmission

Comparative analysis: assess the causality of associations between social cognition and socially transmitted parasites; e.g., test for associations between lice species richness/prevalence and socia learning performances in birds using path analyses

Comparative analysis: assess the causality of associations between cognition, parasites, and ecological generalism; e.g., test for associations between blood parasite richness/prevalence and general cognition in birds (innovation rate and brain size) using path analyses Comparative analyses: assess the causality of associations between cognition, parasites, and life history; e.g., test for associations between parasite richness/prevalence and general cognition in birds (innovation rate and brain size) using path analyses

\section{Consider the confounding effects of} diet and habitat breadth

Demonstrate that innovative anti-parasite behaviors involve cognition

The time scale can have strong importance (compare short/long term effects; compare the effects of manipulation during/after development) Determine how an eventual change in cognition following infection favors the parasite's cycle completion

Consider social organization and interspecific interactions in the analyses

Consider diet and habitat breadth

Consider different life history traits (especially longevity and breeding frequency)

Consider a diversity of immune traits experiments may be easier to conduct on non-bird model species (e.g. guppies or arthropods); comparative analyses using path analyses can be considered in birds, e.g., relating brain size/innovation rates and immune traits

Using genomic and proteomic approaches to assess immune traits/cognition pleiotropy and molecular mechanisms affecting anti-parasite behavior in wild animals
Consider a large number of

loci/genotypes and a variety of different cognitive traits

For each mechanism, we underline important aspects to take into account when developing experimental protocols or comparative analyses. 
(ideally, over long periods of time), and consider a combination of parasitism measures and immune traits to relate to measures of cognitive performances.

\section{Across-Species Analyses}

In line with the paucity of studies within species, only a few comparisons have been conducted across species in birds. To our knowledge, only four comparative studies have looked for associations between proxies of cognition, immunocompetence, and parasitism (Table 1). Examining 45 bird species, Garamszegi et al. (2007) found a positive association between the prevalence of haematozoa parasites and species rate of foraging innovations. Similarly, in an analysis of 55 bird species, Soler et al. (2012) found that bacterial density on eggshells was increased in species with higher rates of foraging innovations. In a third analysis, working this time at the family level and considering 108 different families, Vas et al. (2011) found that the richness of amblyceran (but not ischnoceran) lice species was higher in more innovative families. The three studies thus reveal a similar pattern: an increase in either parasite species richness, parasite prevalence or intensity of infection in more innovative species. These patterns suggest that innovative species are exposed to more parasites, e.g., because innovativeness is part of a generalist lifestyle exposing individuals to a diversity of environmental conditions, or because foraging innovations per se increase the probability of encountering (new) pathogens. Vas et al. (2011) suggested that innovative species may also be more social, another factor that increases exposure to parasites by increasing conspecific contacts. Direct evidence for an association between innovativeness and sociality in birds is however lacking. In addition to associations between parasitism and foraging innovation rates, associations between proxies of cognition and immunocompetence have also been tested and detected at the inter-specific level. The relative size of the bursa of Fabricius (59 species) and spleen (127 species), two organs involved in immune defense, covaried positively with the relative size of the brain in male birds (Møller et al., 2005). Similarly, more innovative birds also had a relatively larger bursa of Fabricius (77 species), spleen (97 species), and thymus (48 species) (Garamszegi et al., 2007). These patterns thus suggest a higher investment in immune defenses in species with a larger brain and more innovative behavior. In line with the results considering parasites instead of immune traits, these associations thus also support the idea that a larger brain or a higher innovativeness involves a higher exposure to parasites, thus selecting for a better immunocompetence.

Contrary to the studies at the intra-specific level, inter-specific comparative analyses thus seem to yield relatively consistent results. However, it is important to notice three key aspects. First, all of these studies are either restricted to the Western Palearctic birds (Møller et al., 2005; Garamszegi et al., 2007; Soler et al., 2012) - reducing the generality of the results - or conducted at the avian family level (Vas et al., 2011) - thus ignoring withinfamily variation, although closely related species can show strong differences in cognitive abilities (e.g., Audet et al., 2018).

Second, the causality is again difficult to establish, especially because the link between the cognitive traits (here, foraging innovation) and the type of parasites considered is not obvious. Why foraging innovations should relate to the richness of lice species is unclear, for example, since the transmission mode of these parasites is not directly related to their host's foraging behavior. A more direct relationship between foraging innovativeness and food-related parasites (such as helminths) may be easier to interpret, but this association has not been tested. In primates, McCabe et al. (2014) showed that the richness of socially transmitted parasite species increased with the host rates of social learning, whereas the richness of environmentally transmitted parasite species increased with the diversity of extractive foraging behaviors, suggesting direct causal relationships. Considering parasites that have a clear link with the cognitive trait measured, e.g., because their transmission mode is likely affected by this cognitive trait, is a key step toward a better understanding of host cognition/parasites relationships.

Finally, previous studies linking cognition and parasitism not only focused on different types of parasites, but also adopted different metrics to quantify the level of parasitism. Prevalence (Garamszegi et al., 2007), intensity of infection (Soler et al., 2012), or species richness (Vas et al., 2011) were used in these studies, metrics that are likely affected by different parameters (Shaw et al., 2018) and cognitive traits.

\section{DEVELOPING A CAUSAL FRAMEWORK}

Most of the studies testing for associations between cognition and parasitism in birds are correlative, and inferring the responsible processes is still a challenge. In this section, we propose three scenarios and the associated mechanisms predicting different causal and non-causal associations between cognition, parasites, and immune traits (Figure 1). Our aim is to clarify the mechanisms that can explain associations between cognitive traits and either parasitism or immune traits. In addition, we provide examples and suggestions of future studies to better determine the importance of each scenario (Table 2). Note that the proposed scenarios are not mutually exclusive.

\section{Scenario 1: Cognition Causally Affects Parasitism}

Under the first scenario, associations between cognition and parasitism are expected because of a causal relationship: cognition causes a change in parasitism. Such a relationship can be due to two main mechanisms, either cognitive activities increase exposure to parasites, or cognitive abilities help in avoiding or responding to parasites.

\section{Mechanism 1.1: Cognitive Activities Increase Exposure to Parasites}

A higher exposure to parasites can be the causal result of the expression of a cognitive trait. Cognitive processes, by definition, involve the collection of information on the environment, which may entail an increased exposure to environmental pathogens. For example, as an individual expresses a new foraging behavior (either by ingesting a new type of food, or using a new foraging technique), it may at the same time be exposed to parasites that it 
would not have encountered otherwise. Activity and exploration level are indeed good predictors of exposure to parasites (e.g., Koprivnikar et al., 2012). Innovative individuals may thus experience a higher exposure to parasites as a direct consequence of their innovative behavior. Although the comparative studies mentioned in the previous sections suggest an increased parasite pressure in more innovative bird species, the causality of the association has not yet been demonstrated, and non-causal links cannot be excluded (see section "Scenario 3: Non-Causal Associations Between Cognition and Parasitism”).

\section{Mechanism 1.2: Cognitive Abilities Help to Avoid or Respond to Parasites}

Host cognitive abilities can, in some cases, directly help a host to either avoid or resist parasites. By exploiting habitats or developing foraging behaviors that are not used by most of their conspecifics, innovative individuals may, for example, limit their contacts with conspecifics, decreasing their exposure to parasites. Evidence for this pattern is however missing. In addition, individuals may learn to recognize and avoid infected individuals - as in mandrills which can recognize the smell of individuals infected by protozoan parasites, and avoid grooming them (Poirotte et al., 2017; see also reviews on parasite avoidance behaviors: Hart and Hart, 2018; Kavaliers and Choleris, 2018; Sarabian et al., 2018). Hosts can also learn to avoid contact with pathogens - as in the Nematode Caenorhabditis elegans that learns to associate the smell of a pathogenic bacteria with a hazard (Zhang et al., 2005). Innovativeness may also yield novel ways of counteracting external and internal pathogens. In primates, a growing literature on self-medication suggests that several ape species ingest plants that have anti-parasitic properties. Chimpanzees, for example, chew the piths of Vernonia amygdalina and swallow Aspilia leaves, which are thought to facilitate the expulsion of intestinal nematodes and cestodes (Huffman, 2001). Gibbons in Thailand are also thought to use Gironniera nervosa leaves for similar purposes (Barelli and Huffman, 2017). A recent comparative analysis found that primate species with a larger absolute brain are more likely to self-medicate, suggesting that self-medication is, to some degree, cognitively demanding (Neco et al., 2019).

More direct evidence for a link between cognition and parasite avoidance comes from studies in birds. Several reports suggest, for instance, innovative ways of dealing with external parasites and nest pathogens. Over 200 avian species frequently apply formic acid secreted by ants during preening (Bush and Clayton, 2018). Occasionally, "anting" innovations have been observed, where substances likely to have anti-parasite effects are also applied. Cimadom et al. (2016) report that warbler finches (Certhidea olivacea) in the Galapàgos tear off leaves of Psidium galapageium and preen with them either directly or after chewing and applying a mixture of saliva and mashed leaf. Several species of grackles have also been described "anting" with different substances (e.g., mothballs, Borgelt, 1960; Clark et al., 1990; or lime, Clayton and Vernon, 1993; see also Parks, 1945; Groff and Brackbill, 1946; Laskey, 1948). Another use of innovative techniques by birds to combat pathogens involves the incorporation of substances like cigarette butts and fumigated cotton to avian nests. Suárez-Rodríguez et al. (2013) found that $80 \%$ of house sparrow and house finch nests at an urban site in Mexico contained cigarette butts, while Knutie et al. (2014) witnessed Darwin's finches taking cotton from laundry lines, leading the researchers to install field dispensers of cotton fumigated with permethrin that the birds bring back to their nests.

The role of cognition in the emergence of these antiparasite innovations needs to be demonstrated. Importantly, if behavioral plasticity is a general trait that can apply to multiple situations, we would expect novel anti-parasite responses to occur in the same species that show high rates of innovation in the most intensively studied domain, foraging (Lefebvre, 2011). House sparrows, who incorporate tobacco in their nests, Darwin's finches, who take cotton from laundry lines, and grackles, who ant with mothballs, are among the birds with the highest rate of foraging innovation (Overington et al., 2009). Foraging innovations in birds (and primates, Reader and Laland, 2002) are associated with larger neural substrates, especially association areas (Lefebvre et al., 1997; Timmermans et al., 2000; Overington et al., 2009). This suggests that the enhanced cognitive processing associated with larger association areas might also apply to antiparasite responses.

Similarly, while there is considerable evidence of antiparasitic behaviors, their efficacy has not been demonstrated and we cannot eliminate the possibility that their usage is simply based on random use of materials. "Anting" substitutes never seem to involve neutral objects (Clark et al., 1990), but many birds incorporate plastic and other anthropogenic substances into their nests even if they do not have any antiparasitic properties. In a recent review, Bush and Clayton (2018) stressed that rigorous experimental demonstrations of the purposefulness and efficacy of substitute anti-parasitic substances are still lacking. A few studies have however provided intriguing results on the anti-parasitic properties of several of the substances. Cimadom et al. (2016) showed that extracts from the $P$. galapageium leaves used in Darwin's finch "anting" have negative effects on both mosquitoes and invasive hematophagous fly (Philornis downsi) adults and larvae. Clayton and Vernon (1993) exposed lice-infested pigeon feathers to both lime juice and lime rinds and found that the latter had a strong negative effect on them, a finding supported by Weldon et al. (2011). Suárez-Rodríguez et al. (2013) found that mite traps containing cellulose from smoked cigarette butts attracted significantly fewer ectoparasites than traps with non-smoked cellulose. Care is therefore needed in interpreting observations of anti-parasite innovations in birds, but experimental evidence suggests that Simmons (1966) skepticism on the functionality of substitute substances, which he saw as developmental errors in the learning process of anting responses, might be unfounded. Paradoxically, the exposure to pathogens that is associated with flexible, opportunistic generalist feeding could thus be greater than we think, because innovative anti-pathogen behaviors, if frequent enough, might 
be reducing the parasite loads we are actually measuring on innovative feeders.

\section{Scenario 2: Parasitism Causally Affects Cognition}

The second scenario also considers a direct causal relationship between cognition and parasites, but the direction of the causality is reversed: parasites change their host cognition.

\section{Mechanism 2.1: The Cognitive Cost of Parasite Infection}

In line with the idea that host behavior can be altered by pathogen infection, especially via a change in the host state (e.g., body condition), pathogen infection may cause a decrease in cognitive performance. For example, in the Ambon damselfish (Pomacentrus amboinensis), experimental infection with gnathiid parasites decreased individual performance at a visual discrimination test (Binning et al., 2018). To our knowledge, there is no direct evidence of a change in cognition after a pathogen infection in wild birds. This is however most likely due to a lack of studies: we are aware of only one study that aimed at changing parasite infection to test its effect on cognition in wild birds; as mentioned earlier, Cauchard et al. (2016) found no effect of an anti-malaria drug on problem solving performance in great tits. In a study on a captive population of zebra finches (Taeniopygia guttata), Grindstaff et al. (2012) showed a long-term effect of an immune challenge during the juvenile stage on the learning performance of adult males. Also working with captive zebra finches, Uysal et al. (2018) demonstrated that the morphology of adult brains was affected by a simulated viral infection during the hatchling stage. The activation of the immune system in response to a pathogen infection can thus have long-term effects on the host cognition, and additional studies would likely bring valuable information on the immediate and long-term effects of pathogen infections on wild bird cognition. Some pathogens are also known to directly infect the nervous system; in birds, they have mostly been investigated in veterinary sciences, using poultry as model species (e.g., the paramyxovirus responsible for the Newcastle disease in chickens; Butt et al., 2019). Experimental infection and treatment of infected individuals, ideally on wild birds, are likely the best approaches to further test the importance of this mechanism.

\section{Mechanism 2.2: Parasites Manipulate Their Host Cognition}

Parasites may also directly alter their host decision-making to facilitate their own transmission. A diversity of studies have demonstrated that some parasites manipulate their host behavior for their own benefit (e.g., to favor their transfer to another host, Lafferty and Morris, 1996; Moore, 2002). Host cognitive responses could be similarly affected by parasite manipulation. For example, parasites could reduce a host's ability to learn about aversive consequences of its dietary choices, facilitating repeated ingestion despite cues that would normally lead to food avoidance. However, to our knowledge, this idea has not been tested directly.

\section{Scenario 3: Non-causal Associations Between Cognition and Parasitism}

Non-causal associations between cognition and parasitism are also expected, e.g., because they are both affected by a third factor. The following three mechanisms predict such indirect associations.

\section{Mechanism 3.1: Cognition Is Associated With Lifestyles Affecting Parasitism}

Animals' lifestyles are known to affect their exposure to parasites for several reasons. Since cognition co-evolves with lifestyles (e.g., see Ducatez et al., 2015; Sol et al., 2016), indirect associations between cognition and parasites are expected. Three trait features of animals' lifestyles are especially likely to affect their exposure to parasites and co-evolve with cognition: sociality, ecological generalism, and life history.

\section{Mechanism 3.1.1: social intelligence and social parasites}

As expected under the "social intelligence" hypothesis (Byrne and Whiten, 1989; Whiten and Byrne, 1997), an increased complexity of social organization may select for cognitive skills favoring social interactions (e.g., Ashton et al., 2018). Since social interactions are also likely to favor the transfer of socially transmitted pathogens, associations between social cognition (e.g., social learning) and socially transmitted pathogens are expected. In primates, the higher richness of socially transmitted parasites in species where social learning is more often recorded is in line with this idea (McCabe et al., 2014). Other cognitive traits may also be indirectly associated with socially transmitted parasitism, because of co-variation between these traits and social cognition (e.g., see Reader et al., 2011; see also Villa et al., 2016). Note however that sociality may also, in some cases, decrease parasite pressure, for example, via social defenses such as allogrooming/allopreening, or because of dilution effects (see Mooring and Hart, 1992), in which case social species should be less parasitized (e.g., Bordes et al., 2007). Innovative species with allogrooming and with close social contact leading to dilution thus need to be singled out here, with the prediction that their parasite loads should be lower than species without the social effects.

\section{Mechanism 3.1.2: ecological generalism, cognition, and parasite exposure}

Ecological generalists are often characterized by their higher cognitive abilities (e.g., larger brain or higher innovation rates; Overington et al., 2011; Ducatez et al., 2015). Because occurring in a wider diversity of habitats or exploiting a higher diversity of foods is likely to increase the diversity of parasites a given organism is exposed to (e.g., Gutiérrez et al., 2017, 2019), the generalist lifestyle of organisms with higher cognitive abilities should increase the rate of parasitism.

\section{Mechanism 3.1.3: life history, cognition, and parasite exposure}

Large brains, relative to body size, are more likely to evolve in long-lived species (Allman et al., 1993; Van Schaik and Deaner, 2003; Ricklefs, 2004; Sol et al., 2007; Lefebvre and Sol, 2008; González-Lagos et al., 2010). Similarly, innovation propensity 
covaries with life history in birds, long-lived species being also more innovative (Sol et al., 2016). Differences in parasitism associated with variation in life history could thus indirectly result in associations between parasitism and cognition. Host longevity is, for example, a predictor of parasite richness in some taxa, long-lived species tending to accumulate a higher diversity of parasite species (Poulin and Morand, 2000). Indirectly, largebrained and more innovative species should thus have an increased parasite species richness.

It is noticeable that these different lifestyles are not only associated with differences in cognition and parasite exposure, but also with differences in immunocompetence (see Figure 1; we consider here a broad definition of immunocompetence, i.e., the ability to produce an immune response following exposure to an antigen). For example, the pace-of-life syndrome hypothesis suggests that animals differ in a suite of physiological traits (including immune traits) that have coevolved with particular life histories (Ricklefs and Wikelski, 2002). Behavioral (Réale et al., 2010) and cognitive (Sih and Del Giudice, 2012) traits are also expected to be part of this general syndrome, shaping variation in cognition, behavior, and physiology according to an organism's life history. As a result, immune and cognitive traits may be associated because of co-selection processes, e.g., because in long-lived species, both a higher investment in immunocompetence and in learning abilities are favored. Long-lived species may thus, as a result, have a lower rate of parasitism because of their investment in better immune defenses, while also benefiting from better learning abilities. Modern comparative methods such as phylogenetic path analyses (Hardenberg and von Gonzalez-Voyer, 2013), based on large numbers of species and including data on parasitism, immunocompetence, cognitive performances, life history and/or ecological generalism and/or sociality are likely to bring new advances in our understanding of the causal relationships between these different compartments. For example, an association between foraging innovation rate and helminth richness may be mostly due to the higher diet generalism of innovative birds which may expose them to a higher diversity of helminths, rather than to their higher cognitive abilities per se. A path analysis should help in disentangling the causality of this eventual association, and determining whether, after taking into account the effect of diet breadth, foraging innovations still causally affect the richness of helminth species (see also Table 2).

\section{Mechanism 3.2: Brain/Immunocompetence Trade-Offs: The Expensive Tissue Hypothesis}

Anti-parasite defenses are energetically costly (Sheldon and Verhulst, 1996; Hanssen et al., 2004), resulting in evolutionary trade-offs between investment in anti-parasitic defenses and other energetically costly functions (Sheldon and Verhulst, 1996). The brain is especially costly to build and maintain (Aiello and Wheeler, 1995; Isler and van Schaik, 2009), so that a trade-off between investment in cognitive vs immune functions is theoretically expected. In line with this hypothesis, experiments using artificial selection on brain size in guppies (Poecilia reticulata) found that individuals selected for relatively larger brains had a reduced innate (but not adaptive) immune response as compared to fish selected for relatively smaller brains (Kotrschal et al., 2016). Evidence for this hypothesis remains however scarce and the association between brain size and parasites or immune traits is inconsistent. In rodents, species brain size was not associated with either flea or helminth richness (see Bordes et al., 2011). In birds, the relative size of the brain and of organs involved in the immune system tend to be positively correlated (Møller et al., 2005; Garamszegi et al., 2007). This apparent contradiction may relate to methodological and taxonomic differences. Especially, such energetic trade-offs may be difficult to detect via inter-specific comparisons. Long-term trait co-selection, for example, of cognition and immune traits if higher cognitive performance tends to increase parasite exposure, may have led to the evolution of both larger brains and stronger immunocompetence in some species, even if both traits require important energy inputs. Experimental approaches, including artificial selection experiments, are likely a more powerful approach to test the importance of this mechanism (e.g., Kotrschal et al., 2013).

\section{Mechanism 3.3: Molecular Associations and Pleiotropy}

The immune system and the central nervous system share numerous cell types, signaling molecules, processes, pathways and genes. There is considerable communication between the nervous and immune systems, among others through the bloodbrain barrier, a semi-permeable cellular boundary between the brain and the circulating blood flow that allows cells, proteins, and molecules - such as leukocytes, cytokines, and chemokines to travel through it (Abbott et al., 2010).

In humans, the intimate connection between cognition and the immune system is relatively well understood (e.g., see Bilbo and Schwarz, 2012). A wide range of neuropsychological disorders such as schizophrenia, learning disabilities, depression, anxiety, and stress disorders are characterized by abnormal or modified levels of immune components, namely cytokines, growth factors, inflammatory markers, synapse proteins, and immune cell numbers (reviewed in Bilbo and Schwarz, 2012; Theoharides et al., 2013). The modification of a wide variety of inflammatory components, either during development or in adults, is also known to affect both cognitive and immune traits (Bilbo and Schwarz, 2009, 2012; Donzis and Tronson, 2014).

Pleiotropic effects may also explain associations between cognitive and immune traits. Pleiotropy is the influence of a single gene on multiple unrelated phenotypic traits (Tyler et al., 2009). Two studies reported separate pleiotropic effects of two genes, INFG and ACP1, which affect both extravert behavior and immune functions (MacMurray et al., 2014; Napolioni et al., 2014). Other loci were found to display pleiotropic effects on immune system and neuropsychological conditions or diseases that include cognitive impairments. For example, genome-wide association studies (GWAS) have identified several loci in the major histocompatibility complex (MHC) - an acquired immune system component - that were associated with schizophrenia and multiple sclerosis 
(Stefansson et al., 2009; Schizophrenia Psychiatric GenomeWide Association Study (Gwas) Consortium, 2011; Gourraud et al., 2012; Ripke et al., 2013). Other non-MHC related but immunologically relevant genes have also been linked with multiple sclerosis (Sawcer et al., 2011). The above examples suggest that pleiotropic genes affecting both immune function and cognition are also likely to exist in wild animals, causing associations between immune and cognitive traits.

\section{KNOWLEDGE GAPS IN THE PROPOSED FRAMEWORK}

We have proposed three main scenarios under which associations between parasitism and cognitive traits are expected. The mechanisms detailed under these scenarios are not mutually exclusive and can even have opposite effects, increasing the difficulty of developing falsifiable predictions that can distinguish them. Providing a precise guideline on how to thoroughly test the relevance and generality of each mechanism is particularly challenging and beyond the scope of this article, but we discuss here several points that we think should help future studies to provide a mechanistic understanding of cognition-parasite associations (see also Table 2).

One key to further develop our understanding of these interactions is to combine different approaches (including observations, experimental, and comparative studies), while also targeting parasites, metrics of parasitism and cognitive traits that are relevant to test a given mechanism. Empirical studies on captive birds, e.g., experimental infections to test both short term and long-term effects on cognition, would for example be especially informative for mechanisms such as the infection cost. Similarly, artificial selection experiments should favor a better understanding of the importance of energetic trade-offs. In contrast, some mechanisms such as the indirect effects of lifestyles may only be detectable at higher taxonomic levels, using interspecific comparative analyses. The mechanism of parasite transmission is especially important here, as different host behavioral and cognitive strategies will have different effects on parasites being transferred via direct contact between conspecifics, contact with specific food items, or vectors such as mosquitoes (see Table 2 for examples of studies that could bring new elements to understand the importance of the different mechanisms).

Host-parasite interactions are dynamic processes, involving eco-evolutionary processes such as feedback loops and arms races between parasites and their hosts (Price, 1981; Poulin, 2006). Such processes are likely to have major effects on the association between cognitive traits and parasitism, especially via changes in host immunocompetence (though these effects may depend on the host specificity of the parasites considered, see Poulin, 2006). For example, if highly innovative individuals are exposed to more parasites, natural selection is likely to favor innovative individuals that are better able to respond to these parasites. As a result, innovative individuals may evolve better immune defenses. Ultimately, these stronger immune defenses may result in lower parasite prevalence or infection intensity in more innovative individuals. This type of evolutionary feedback loop is a key aspect of host-parasites dynamics (Ezenwa et al., 2016), and can affect both the host and the parasite's evolution, involving changes in host defense, parasite pathogenicity or parasite diversification (Poulin, 2006). Considering both metrics of parasitism and immune traits is thus important to provide integrated information on how cognition and parasites are associated. Immunocompetence is complex and involves a diversity of traits, and investigating interactions between cognitive traits and immunocompetence also requires careful consideration of the immune traits measured. Measurements such as the PHA response are easy to take on wild individuals, but only cover a small part of the story, and a diversity of other immune traits should be considered (Monceau et al., 2017). Studies considering both innate and acquired immune responses would, for example, provide more complete information on the importance of previous exposure to pathogens in shaping associations between cognition and immune traits (e.g., see Kotrschal et al., 2016).

Finally, note that we focused on the most likely mechanisms based on the literature, though other mechanisms may also play a role. For example, extra-pair copulation was more likely to occur in innovative than in non-innovative female great tits (Bókony et al., 2017), which could indirectly increase exposure to sexually transmissible pathogens in more innovative birds. Our review has also mostly been written from the perspective of the host, although cognition may also be relevant for the parasite. Although the justification is that most current studies focus on the role of cognition in hosts, the viewpoint of the parasite is particularly relevant considering that some of the mechanisms linking cognition and parasitism are expected to vary depending on the biology of the parasite - notably its virulence, mode of transmission and ability to respond to the host defense.

\section{CONCLUDING REMARKS}

The studies that have investigated associations between parasites and cognition do not yet allow us to rank the relative importance of the different mechanisms and scenarios explaining how and why cognitive traits and parasitism interact. This is likely to change in the near future, with the growing availability of fully resolved phylogenetic trees on large taxonomic groups (e.g., see Jetz et al., 2012 for birds; Upham et al., 2019 for mammals), together with the existence of large datasets on species cognitive traits, immunocompetence and parasites, especially in birds. Combined with modern advanced phylogenetic methods, this information provides the opportunity to test some of the mechanisms proposed in our framework at unprecedented large taxonomic and geographic scales. Experimental studies are also strongly needed. The main challenge is likely to distinguish between causal and non-causal effects, and thus to design experiments to falsify competing predictions. Both for comparative and experimental 
approaches, progress will largely depend on carefully selecting the measure of parasitism (prevalence, infection intensity, or species richness), the characteristics of the parasites (host specificity and parasite transmission mode), the type of cognitive trait (e.g., innovativeness and social learning), and the type of defensive trait (e.g., innate or acquired immunity) measured. Understanding these causal effects is essential in assessing the role of parasites in the evolution of cognition and, conversely, the role of host cognition in the evolution of both hosts and their parasites. Ultimately, acquiring a better understanding of causal effects in cognition-parasite associations may provide fundamental information on the role played by cognition in zoonoses and disease dynamics.

\section{AUTHOR CONTRIBUTIONS}

SD wrote the first draft of the manuscript. All authors contributed to the formulation, writing, and revision of this

\section{REFERENCES}

Abbott, N. J., Patabendige, A. A. K., Dolman, D. E. M., Yusof, S. R., and Begley, D. J. (2010). Structure and function of the blood-brain barrier. Neurobiol. Dis. 37, 13-25. doi: 10.1016/j.nbd.2009.07.030

Ader, R., Felten, D., and Cohen, N. (2006). Psychoneuroimmunology, 4th Edn. Cambridge, MA: Academic Press.

Aiello, L. C., and Wheeler, P. (1995). The expensive-tissue hypothesis: the brain and the digestive system in human and primate evolution. Curr. Anthropol. 36, 199-221. doi: 10.1086/204350

Allman, J., McLaughlin, T., and Hakeem, A. (1993). Brain weight and life-span in primate species. PNAS 90, 118-122. doi: 10.1073/pnas.90.1.118

Anderson, A., and McMullan, R. (2018). Neuronal and non-neuronal signals regulate Caernorhabditis elegans avoidance of contaminated food. Philos. Trans. R. Soc. Lond. B Biol. Sci. 373:20170255. doi: 10.1098/rstb.2017.0255

Anderson, R. M., and May, R. M. (1979). Population biology of infectious diseases: Part I. Nature 280, 361. doi: 10.1038/280361a0

Arneberg, P. (2002). Host population density and body mass as determinants of species richness in parasite communities: comparative analyses of directly transmitted nematodes of mammals. Ecography 25, 88-94. doi: 10.1034/j.16000587.2002.250110.x

Arriero, E., and Møller, A. P. (2008). Host ecology and life-history traits associated with blood parasite species richness in birds. J. Evol. Biol. 21, 1504-1513. doi: 10.1111/j.1420-9101.2008.01613.x

Ashton, B. J., Ridley, A. R., Edwards, E. K., and Thornton, A. (2018). Cognitive performance is linked to group size and affects fitness in Australian magpies. Nature 554, 364-367. doi: 10.1038/nature25503

Audet, J. N., Ducatez, S., and Lefebvre, L. (2016). The town bird and the country bird: problem solving and immunocompetence vary with urbanization. Behav. Ecol. 27, 637-644. doi: 10.1093/beheco/arv201

Audet, J. N., Kayello, L., Ducatez, S., Perillo, S., Cauchard, L., Howard, J. T., et al. (2018). Divergence in problem-solving skills is associated with differential expression of glutamate receptors in wild finches. Sci. Adv. 4:eaao6369. doi: 10.1126/sciadv.aao6369

Barber, I., and Dingemanse, N. J. (2010). Parasitism and the evolutionary ecology of animal personality. Philos. Trans. R. Soc. B 365, 4077-4088. doi: 10.1098/rstb. 2010.0182

Barelli, C., and Huffman, M. A. (2017). Leaf swallowing and parasite expulsion in Khao Yai white-handed gibbons (Hylobates lar), the first report in an Asian ape species. Am. J. Primatol. 79:e22610. doi: 10.1002/ajp.22610

Bilbo, S. D., and Schwarz, J. M. (2009). Early-Life programming of later-life brain and behavior: a critical role for the immune system. Front. Behav. Neurosci. 3:14. doi: 10.3389/neuro.08.014.2009 manuscript, made direct intellectual contributions, and approved its publication.

\section{FUNDING}

This work was supported by funds from the Spanish Government (CGL2017-90033-P) to DS. SD was supported by a McGill University-CREAF collaboration agreement partially funded by a Discovery Grant from NSERC Canada to LL. J-NA was funded by a Banting Postdoctoral Fellowship from Canada.

\section{ACKNOWLEDGMENTS}

This article benefited from useful conversations and feedback from Jayna DeVore. The authors are grateful to the editor and the two reviewers that helped in improving a previous version of the manuscript.

Bilbo, S. D., and Schwarz, J. M. (2012). The immune system and developmental programming of brain and behavior. Front. Neuroendocrin. 33:267-286. doi: 10.1016/j.yfrne.2012.08.006

Binning, S. A., Roche, D. G., Grutter, A. S., Colosio, S., Sun, D., Miest, J., et al. (2018). Cleaner wrasse indirectly affect the cognitive performance of a damselfish through ectoparasite removal. Proc. Biol. Sci. 285:20172447. doi: 10.1098/rspb.2017.2447

Bókony, V., Lendvai, A. Z., Vagasi, C. I., Patras, L., Pap, P. L., Nemeth, J., et al. (2014). Necessity or capacity? Physiological state predicts problem-solving performance in house sparrows. Behav. Ecol. 25, 124-135. doi: 10.1093/beheco/ art094

Bókony, V., Pipoly, I., Szabó, K., Preiszner, B., Vincze, E., Papp, S., et al. (2017). Innovative females are more promiscuous in great tits (Parus major). Behav. Ecol. 28, 579-588. doi: 10.1093/beheco/arx001

Bordes, F., Blumstein, D. T., and Morand, S. (2007). Rodent sociality and parasite diversity. Biol. Lett. 3, 692-694. doi: 10.1098/rsbl.2007.0393

Bordes, F., Morand, S., Kelt, D. A., and Van Vuren, D. H. (2009). Home range and parasite diversity in mammals. Am. Nat. 173, 467-474. doi: 10.1086/597227

Bordes, F., Morand, S., and Krasnov, B. R. (2011). Does investment into "expensive" tissue compromise anti-parasitic defence? Testes size, brain size and parasite diversity in rodent hosts. Oecologia 165, 7-16. doi: 10.1007/s00442-010-1743-9

Borgelt, L. H. (1960). Common grackles anting with moth balls. Wilson Bull. 72, 408-409.

Branch, C. L., Pitera, A. M., Kozlovsky, D. Y., Bridge, E. S., and Pravosudov, V. V. (2019). Smart is the new sexy: female mountain chickadees increase reproductive investment when mated to males with better spatial cognition. Ecol. Lett. 22, 897-903. doi: 10.1111/ele.13249

Bush, S. E., and Clayton, D. H. (2018). Anti-parasite behaviour of birds. Philos. Trans. R. Soc. B 373:20170196. doi: 10.1098/rstb.2017.0196

Butt, S. L., Moura, V. M. B. D., Susta, L., Miller, P. J., Hutcheson, J. M., CardenasGarcia, S., et al. (2019). Tropism of Newcastle disease virus strains for chicken neurons, astrocytes, oligodendrocytes, and microglia. BMC Vet. Res. 15:317. doi: 10.1186/s12917-019-2053-z

Byrne, R., and Whiten, A. (1989). Machiavellian Intelligence: Social Expertise and the Evolution of Intellect in Monkeys, Apes, and Humans. Oxford: Clarendon Press.

Cauchard, L., Angers, B., Boogert, N. J., and Doligez, B. (2016). Effect of an anti-malaria drug on behavioural performance on a problem-solving task: an experiment in wild great tits. Behav. Process 133, 24-30. doi: 10.1016/j.beproc. 2016.10.012

Cauchard, L., Boogert, N. J., Lefebvre, L., Dubois, F., and Doligez, B. (2013). Problem-solving performance is correlated with reproductive success in a wild bird population. Anim. Behav. 85, 19-26. doi: 10.1016/j.anbehav.2012.10.005 
Cimadom, A., Causton, C., Cha, D. H., Damiens, D., Fessl, B., Hood-Nowotny, R., et al. (2016). Darwin's finches treat their feathers with a natural repellent. Sci. Rep. 6:34559. doi: 10.1038/srep34559

Clark, C. C., Clark, L., and Clark, L. (1990). “Anting” behavior by common grackles and european starlings. Wilson Bull. 102, 167-169.

Clayton, D. H., and Moore, J. (1997). Host-Parasite Evolution: General Principles and Avian Models. Oxford: Oxford University Press.

Clayton, D. H., and Vernon, J. G. (1993). Common grackle anting with lime fruit and its effect on ectoparasites. Auk 110, 951-952. doi: 10.2307/4088657

Cole, E. F., Morand-Ferron, J., Hinks, A. E., and Quinn, J. L. (2012). Cognitive ability influences reproductive life history variation in the Wild. Curr. Biol. 22, 1808-1812. doi: 10.1016/j.cub.2012.07.051

Donzis, E. J., and Tronson, N. C. (2014). Modulation of learning and memory by cytokines: signaling mechanisms and long term consequences. Neurobiol. Learn. Mem. 0, 68-77. doi: 10.1016/j.nlm.2014.08.008

Ducatez, S., Audet, J.-N., and Lefebvre, L. (2019). Speed-accuracy trade-off, detour reaching and response to PHA in Carib grackles. Anim. Cogn. 22, 625-633. doi: 10.1007/s10071-019-01258-1

Ducatez, S., Clavel, J., and Lefebvre, L. (2015). Ecological generalism and behavioural innovation in birds: technical intelligence or the simple incorporation of new foods? J. Anim. Ecol. 84, 79-89. doi: 10.1111/1365-2656. 12255

Dunn, J. C., Cole, E. F., and Quinn, J. L. (2011). Personality and parasites: sex-dependent associations between avian malaria infection and multiple behavioural traits. Behav. Ecol. Sociobiol. 65, 1459-1471. doi: 10.1007/s00265011-1156-8

Ezenwa, V. O., Archie, E. A., Craft, M. E., Hawley, D. M., Martin, L. B., Moore, J., et al. (2016). Host behaviour-parasite feedback: an essential link between animal behaviour and disease ecology. Proc. Biol. Sci. 283:20153078. doi: 10. 1098/rspb.2015.3078

Fristoe, T. S., Iwaniuk, A. N., and Botero, C. A. (2017). Big brains stabilize populations and facilitate colonization of variable habitats in birds. Nat. Ecol. Evol. 1, 1706-1715. doi: 10.1038/s41559-017-0316-2

Garamszegi, L. Z., Erritzøe, J., and Møller, A. P. (2007). Feeding innovations and parasitism in birds. Biol. J. Linn. Soc. 90, 441-455. doi: 10.1111/j.1095-8312. 2007.00733.x

Gegear, R. J., Otterstatter, M. C., and Thomson, J. D. (2006). Bumble-bee foragers infected by a gut parasite have an impaired ability to utilize floral information. Proc. Biol. Sci. 273:1073-1078. doi: 10.1098/rspb.2005.3423

Gómez-Moracho, T., Heeb, P., and Lihoreau, M. (2017). Effects of parasites and pathogens on bee cognition. Ecol. Entomol. 42, 51-64. doi: 10.1111/een.12434

González-Lagos, C., Sol, D., and Reader, S. M. (2010). Large-brained mammals live longer. J. Evol. Biol. 23, 1064-1074. doi: 10.1111/j.1420-9101.2010.01976.x

Gourraud, P.-A., Harbo, H. F., Hauser, S. L., and Baranzini, S. E. (2012). The genetics of multiple sclerosis: an up-to-date review. Immunol. Rev. 248, 87-103. doi: 10.1111/j.1600-065X.2012.01134.x

Grindstaff, J. L. (2016). Developmental immune activation programs adult behavior: insight from research on birds. Curr. Opin. Behav. Sci. 7, 21-27. doi: 10.1016/j.cobeha.2015.10.006

Grindstaff, J. L., Hunsaker, V. R., and Cox, S. N. (2012). Maternal and developmental immune challenges alter behavior and learning ability of offspring. Horm. Behav. 62, 337-344. doi: 10.1016/j.yhbeh.2012. 04.005

Groff, M. E., and Brackbill, H. (1946). Purple grackles "anting” with walnut juice. AUK 63, 246-247. doi: 10.2307/4080021

Gutiérrez, J. S., Piersma, T., and Thieltges, D. W. (2019). Micro- and macroparasite species richness in birds: the role of host life history and ecology. J. Anim. Ecol. 88, 1226-1239. doi: 10.1111/1365-2656.12998

Gutiérrez, J. S., Rakhimberdiev, E., Piersma, T., and Thieltges, D. W. (2017). Migration and parasitism: habitat use, not migration distance, influences helminth species richness in Charadriiform birds. J. Biogeogr. 44, 1137-1147. doi: 10.1111/jbi.12956

Hanssen, S. A., Hasselquist, D., Folstad, I., and Erikstad, K. E. (2004). Costs of immunity: immune responsiveness reduces survival in a vertebrate. Proc. Biol. Sci. 271, 925-930. doi: 10.1098/rspb.2004.2678

Hardenberg, A., and von Gonzalez-Voyer, A. (2013). Disentangling evolutionary cause-effect relationships with phylogenetic confirmatory path analysis. Evolution 67, 378-387. doi: 10.1111/j.1558-5646.2012.01790.x
Hart, B. L., and Hart, L. A. (2018). How mammals stay healthy in nature: the evolution of behaviours to avoid parasites and pathogens. Philos. Trans. R. Soc. B 373, 20170205. doi: 10.1098/rstb.2017.0205

Huffman, M. A. (2001). Self-Medicative behavior in the African great apes: an evolutionary perspective into the origins of human traditional medicine. Bioscience 51:651. doi: 10.1641/0006-3568(2001)051[0651:smbita]2.0.co;2

Isler, K., and van Schaik, C. P. (2009). The expensive brain: a framework for explaining evolutionary changes in brain size. J. Hum. Evol. 57, 392-400. doi: 10.1016/j.jhevol.2009.04.009

Jetz, W., Thomas, G. H., Joy, J. B., Hartmann, K., and Mooers, A. O. (2012). The global diversity of birds in space and time. Nature 491, 444-448. doi: 10.1038 /nature11631

Kamiya, T., O’Dwyer, K., Nakagawa, S., and Poulin, R. (2014). What determines species richness of parasitic organisms? A meta-analysis across animal, plant and fungal hosts. Biol. Rev. 89, 123-134. doi: 10.1111/brv.12046

Kavaliers, M., and Choleris, E. (2018). The role of social cognition in parasite and pathogen avoidance. Philos. Trans. R. Soc. B 373:20170206. doi: 10.1098/rstb. 2017.0206

Knutie, S. A., McNew, S. M., Bartlow, A. W., Vargas, D. A., and Clayton, D. H. (2014). Darwin's finches combat introduced nest parasites with fumigated cotton. Curr. Biol. 24, R355-R356. doi: 10.1016/j.cub.2014.03.058

Koprivnikar, J., Gibson Chris, H., and Redfern Julia, C. (2012). Infectious personalities: behavioural syndromes and disease risk in larval amphibians. Proc. Biol. Sci. 279, 1544-1550. doi: 10.1098/rspb.2011.2156

Kortet, R., Hedrick, A. V., and Vainikka, A. (2010). Parasitism, predation and the evolution of animal personalities. Ecol. Lett. 13, 1449-1458. doi: 10.1111/j.14610248.2010.01536.x

Kotrschal, A., Kolm, N., and Penn, D. J. (2016). Selection for brain size impairs innate, but not adaptive immune responses. Proc. Biol. Sci. 283:20152857. doi: 10.1098/rspb.2015.2857

Kotrschal, A., Rogell, B., Bundsen, A., Svensson, B., Zajitschek, S., Brännström, I., et al. (2013). Artificial selection on relative brain size in the guppy reveals costs and benefits of evolving a larger brain. Curr. Biol. 23, 168-171. doi: 10.1016/j.cub.2012.11.058

Lafferty, K. D., and Morris, A. K. (1996). Altered behavior of parasitized killifish increases susceptibility to predation by bird final hosts. Ecology 77, 1390-1397. doi: $10.2307 / 2265536$

Laskey, A. R. (1948). Bronzed grackle anointing plumage with orange-skin. Wilson Bull. 60, 244-245.

Lefebvre, L. (2011). Taxonomic counts of cognition in the wild. Biol. Lett. 7, 631-633. doi: 10.1098/rsbl.2010.0556

Lefebvre, L., and Sol, D. (2008). Brains, lifestyles and cognition: are there general trends? Brain Behav. Evol. 72, 135-144. doi: 10.1159/000151473

Lefebvre, L., Whittle, P., Lascaris, E., and Finkelstein, A. (1997). Feeding innovations and forebrain size in birds. Anim. Behav. 53, 549-560. doi: 10.1006/ anbe. 1996.0330

Lindenfors, P., Nunn, C. L., Jones, K. E., Cunningham, A. A., Sechrest, W., and Gittleman, J. L. (2007). Parasite species richness in carnivores: effects of host body mass, latitude, geographical range and population density. Glob. Ecol. Biogeogr. 16, 496-509. doi: 10.1111/j.1466-8238.2006.00301.x

Lopes, P. C. (2017). Why are behavioral and immune traits linked? Horm. Behav. 88, 52-59. doi: 10.1016/j.yhbeh.2016.09.008

MacArthur, R. H., and Wilson, E. O. (1967). The Theory of Island Biogeography. Princeton: University Press.

MacMurray, J., Comings, D. E., and Napolioni, V. (2014). The gene-immunebehavioral pathway: Gamma-interferon (IFN- $\gamma$ ) simultaneously coordinates susceptibility to infectious disease and harm avoidance behaviors. Brain Behav. Immun. 35, 169-175. doi: 10.1016/j.bbi.2013.09.012

Martin, L. B., Han, P., Lewittes, J., Kuhlman, J. R., Klasing, K. C., and Wikelski, M. (2006). Phytohemagglutinin-induced skin swelling in birds: histological support for a classic immunoecological technique. Funct. Ecol. 20, 290-299. doi: 10.1111/j.1365-2435.2006.01094.x

Martin, T. E., Arriero, E., and Majewska, A. (2011). A trade-off between embryonic development rate and immune function of avian offspring is revealed by considering embryonic temperature. Biol. Lett. 7, 425-428. doi: 10.1098/rsbl. 2010.1031

May, R. M., and Anderson, R. M. (1979). Population biology of infectious diseases: Part II. Nature 280:455. doi: 10.1038/280455a0 
McCabe, C. M., Reader, S. M., and Nunn, C. L. (2014). Infectious disease, behavioural flexibility and the evolution of culture in primates. Proc. Biol. Sci. 282:20140862. doi: 10.1098/rspb.2014.0862

Mobley, M. W., and Gegear, R. J. (2018). Immune-cognitive system connectivity reduces bumblebee foraging success in complex multisensory floral environments. Sci. Rep. 8:5953. doi: 10.1038/s41598-018-24372-5

Møller, A. P., Erritzøe, J., and Garamszegi, L. Z. (2005). Covariation between brain size and immunity in birds: implications for brain size evolution. J. Evol. Biol. 18, 223-237. doi: 10.1111/j.1420-9101.2004.00805.x

Monceau, K., Dechaume-Moncharmont, F.-X., Moreau, J., Lucas, C., Capoduro, R., Motreuil, S., et al. (2017). Personality, immune response and reproductive success: an appraisal of the pace-of-life syndrome hypothesis. J. Anim. Ecol. 86, 932-942. doi: 10.1111/1365-2656.12684

Moore, J. (2002). Parasites and the Behavior of Animals. Oxford: Oxford University Press.

Mooring, M. S., and Hart, B. L. (1992). Animal grouping for protection from parasites: selfish herd and encounter-dilution effects. Behaviour 123, 173-193. doi: $10.1163 / 156853992 \times 00011$

Morand, S., and Poulin, R. (1998). Density, body mass and parasite species richness of terrestrial mammals. Evol. Ecol. 12, 717-727. doi: 10.1023/A:1006537600093

Morand-Ferron, J., Cole, E. F., and Quinn, J. L. (2016). Studying the evolutionary ecology of cognition in the wild: a review of practical and conceptual challenges. Biol. Rev. 91, 367-389. doi: 10.1111/brv.12174

Morand-Ferron, J., and Quinn, J. L. (2011). Larger groups of passerines are more efficient problem solvers in the wild. PNAS 108, 15898-15903. doi: 10.1073/ pnas. 1111560108

Napolioni, V., Murray, D. R., Comings, D. E., Peters, W. R., Gade-Andavolu, R., and MacMurray, J. (2014). Interaction between infectious diseases and personality traits: $\mathrm{ACP}^{*} \mathrm{C}$ as a potential mediator. Infect. Genet. Evol. 26, 267-273. doi: 10.1016/j.meegid.2014.06.002

Neco, L. C., Abelson, E. S., Brown, A., Natterson-Horowitz, B., and Blumstein, D. T. (2019). The evolution of self-medication behaviour in mammals. Biol. J. Linn. Soc. 128, 373-378. doi: 10.1093/biolinnean/blz117

Nunn, C. L., Altizer, S., Jones, K. E., and Sechrest, W. (2003). Comparative tests of parasite species richness in primates. Am. Nat. 162, 597-614. doi: 10.1086/ 378721

Olkowicz, S., Kocourek, M., Luèan, R. K., Porteš, M., Fitch, W. T., HerculanoHouzel, S., et al. (2016). Birds have primate-like numbers of neurons in the forebrain. Proc. Natl. Acad. Sci. U.S.A. 113, 7255-7260. doi: 10.1073/pnas. 1517131113

Overington, S. E., Griffin, A. S., Sol, D., and Lefebvre, L. (2011). Are innovative species ecological generalists? A test in North American birds. Behav. Ecol. 22, 1286-1293. doi: 10.1093/beheco/arr130

Overington, S. E., Morand-Ferron, J., Boogert, N. J., and Lefebvre, L. (2009). Technical innovations drive the relationship between innovativeness and residual brain size in birds. Anim. Behav. 78, 1001-1010. doi: 10.1016/j.anbehav. 2009.06.033

Parks, G. H. (1945). Strange behavior of a bronze grackle. Bird Banding 16:144.

Poirotte, C., Massol, F., Herbert, A., Willaume, E., Bomo, P. M., Kappeler, P. M., et al. (2017). Mandrills use olfaction to socially avoid parasitized conspecifics. Sci. Adv. 3:e1601721. doi: 10.1126/sciadv.16 01721

Poulin, R. (2006). Evolutionary Ecology of Parasites, 2nd Edn. Princeton: Princeton University Press.

Poulin, R. (2013). Parasite manipulation of host personality and behavioural syndromes. J. Exp. Biol. 216, 18-26. doi: 10.1242/jeb.073353

Poulin, R. (2014). Parasite biodiversity revisited: frontiers and constraints. Int. J. Parasit. 44, 581-589. doi: 10.1016/j.ijpara.2014.02.003

Poulin, R., and Morand, S. (2000). The diversity of parasites. Q. Rev. Biol. 75, 277-293.

Price, P. W. (1981). Evolutionary Biology of Parasites. Princeton: Princeton University Press.

Reader, S. M., Hager, Y., and Laland, K. N. (2011). The evolution of primate general and cultural intelligence. Philos. Trans. R. Soc. B 366, 1017-1027. doi: 10.1098/rstb.2010.0342

Reader, S. M., and Laland, K. N. (2002). Social intelligence, innovation, and enhanced brain size in primates. Proc. Natl. Acad. Sci. U.S.A. 99, 4436-4441. doi: 10.1073/pnas.062041299
Réale, D., Garant, D., Humphries, M. M., Bergeron, P., Careau, V., and Montiglio, P.-O. (2010). Personality and the emergence of the pace-of-life syndrome concept at the population level. Philos. Trans. R. Soc. B 365, 4051-4063. doi: $10.1098 /$ rstb. 2010.0208

Ricklefs, R. E. (2004). The cognitive face of avian life histories. Wilson J. Ornithol. 116, 119-133. doi: 10.1676/04-054

Ricklefs, R. E., and Wikelski, M. (2002). The physiology/life-history nexus. Trends Ecol. Evol. 17, 462-468. doi: 10.1016/S0169-5347(02)02578-8

Riotte-Lambert, L., Benhamou, S., Bonenfant, C., and Chamaillé-Jammes, S. (2017). Spatial memory shapes density dependence in population dynamics. Proc. Biol. Sci. 284:20171411. doi: 10.1098/rspb.2017.1411

Ripke, S., O’Dushlaine, C., Chambert, K., Moran, J. L., Kähler, A. K., Akterin, S., et al. (2013). Genome-wide association analysis identifies 13 new risk loci for schizophrenia. Nat. Genet. 45, 1150-1159. doi: 10.1038/ng.2742

Rowe, C., and Healy, S. D. (2014). Measuring variation in cognition. Behav. Ecol. 25, 1287-1292. doi: 10.1093/beheco/aru090

Rutz, C., Klump, B. C., Komarczyk, L., Leighton, R., Kramer, J., Wischnewski, S., et al. (2016). Discovery of species-wide tool use in the Hawaiian crow. Nature 537, 403-407. doi: 10.1038/nature 19103

Sarabian, C., Curtis, V., and McMullan, R. (2018). Evolution of pathogen and parasite avoidance behaviours. Philos. Trans. R. Soc. B 373:256. doi: 10.1098/ rstb.2017.0256

Sawcer, S., Hellenthal, G., Pirinen, M., Spencer, C. C. A., Patsopoulos, N. A., Moutsianas, L., et al. (2011). Genetic risk and a primary role for cell-mediated immune mechanisms in multiple sclerosis. Nature 476, 214-219. doi: 10.1038/ nature 10251

Sayol, F., Downing, P. A., Iwaniuk, A. N., Maspons, J., and Sol, D. (2018). Predictable evolution towards larger brains in birds colonizing oceanic islands. Nat. Commun. 9:2820. doi: 10.1038/s41467-018-05280-8

Sayol, F., Lapiedra, O., Ducatez, S., and Sol, D. (2019). Larger brains spur species diversification in birds. Evolution 73, 2085-2093. doi: 10.1111/evo.13811

Sayol, F., Maspons, J., Lapiedra, O., Iwaniuk, A. N., Székely, T., and Sol, D. (2016). Environmental variation and the evolution of large brains in birds. Nat. Commun. 7:13971. doi: 10.1038/ncomms13971

Schizophrenia Psychiatric Genome-Wide Association Study (Gwas) Consortium. (2011). Genome-wide association study identifies five new schizophrenia loci. Nat. Genet. 43, 969-976. doi: 10.1038/ng.940

Shaw, A. K., Sherman, J., Barker, F. K., and Zuk, M. (2018). Metrics matter: the effect of parasite richness, intensity and prevalence on the evolution of host migration. Proc. Biol. Sci. 285, 20182147. doi: 10.1098/rspb.2018.2147

Sheldon, B. C., and Verhulst, S. (1996). Ecological immunology: costly parasite defences and trade-offs in evolutionary ecology. Trends Ecol. Evol. 11, 317-321. doi: 10.1016/0169-5347(96)10039-2

Shettleworth, S. (2010). Cognition, Evolution, and Behavior. Oxford: Oxford university Press.

Shettleworth, S. J. (2001). Animal cognition and animal behaviour. Anim. Behav. 61, 277-286. doi: 10.1006/anbe.2000.1606

Sih, A., and Del Giudice, M. (2012). Linking behavioural syndromes and cognition: a behavioural ecology perspective. Philos. Trans. R. Soc. B 367, 2762-2772. doi: $10.1098 /$ rstb.2012.0216

Sih, A., Spiegel, O., Godfrey, S., Leu, S., and Bull, C. M. (2018). Integrating social networks, animal personalities, movement ecology and parasites: a framework with examples from a lizard. Anim. Behav. 136, 195-205. doi: 10.1016/j.anbehav. 2017.09.008

Simmons, K. E. L. (1966). Anting and the problem of self-stimulation. J. Zool. 149, 145-162. doi: 10.1111/j.1469-7998.1966.tb03890.x

Sol, D., Duncan, R. P., Blackburn, T. M., Cassey, P., and Lefebvre, L. (2005). Big brains, enhanced cognition, and response of birds to novel environments. Proc. Natl. Acad. Sci. U.S.A. 102, 5460-5465. doi: 10.1073/pnas.0408145102

Sol, D., Sayol, F., Ducatez, S., and Lefebvre, L. (2016). The life-history basis of behavioural innovations. Philos. Trans. R. Soc. B 371:20150187. doi: 10.1098/ rstb.2015.0187

Sol, D., Székely, T., Liker, A., and Lefebvre, L. (2007). Big-brained birds survive better in nature. Proc. Biol. Sci. 274, 763-769. doi: 10.1098/rspb.2006.3765

Soler, J. J., Peralta-Sánchez, J. M., Martín-Vivaldi, M., Martín-Platero, A. M., Flensted-Jensen, E., and Møller, A. P. (2012). Cognitive skills and bacterial load: comparative evidence of costs of cognitive proficiency in birds. Naturwissenschaften 99, 111-122. doi: 10.1007/s00114-011-0875-z 
Sonnenberg, B. R., Branch, C. L., Pitera, A. M., Bridge, E., and Pravosudov, V. V. (2019). Natural selection and spatial cognition in wild food-caching mountain chickadees. Curr. Biol. 29:670-676.e3. doi: 10.1016/j.cub.2019.01.006

Stefansson, H., Ophoff, R. A., Steinberg, S., Andreassen, O. A., Cichon, S., Rujescu, D., et al. (2009). Common variants conferring risk of schizophrenia. Nature 460, 744-747. doi: 10.1038/nature08186

Suárez-Rodríguez, M., López-Rull, I., and Macías Garcia, C. (2013). Incorporation of cigarette butts into nests reduces nest ectoparasite load in urban birds: new ingredients for an old recipe? Biol. Lett. 9:20120931. doi: 10.1098/rsbl.2012. 0931

ten Cate, C., and Healy, S. D. (2017). Avian Cognition. Cambridge: Cambridge University Press.

Theoharides, T. C., Asadi, S., and Patel, A. B. (2013). Focal brain inflammation and autism. J. Neuroinflam. 10:46. doi: 10.1186/1742-2094-10-46

Thornton, A., Isden, J., and Madden, J. R. (2014). Toward wild psychometrics: linking individual cognitive differences to fitness. Behav. Ecol. 25, 1299-1301. doi: 10.1093/beheco/aru095

Timmermans, S., Lefebvre, L., Boire, D., and Basu, P. (2000). Relative size of the hyperstriatum ventrale is the best predictor of feeding innovation rate in birds. BBE 56, 196-203. doi: 10.1159/000047204

Tyler, A. L., Asselbergs, F. W., Williams, S. M., and Moore, J. H. (2009). Shadows of complexity: what biological networks reveal about epistasis and pleiotropy. Bioessays 31, 220-227. doi: 10.1002/bies.200800022

Upham, N. S., Esselstyn, J. A., and Jetz, W. (2019). Ecological causes of uneven diversification and richness in the mammal tree of life. bioRxiv [Preprint] doi: $10.1101 / 504803$

Uysal, A. K., Martin, L. B., Burkett-Cadena, N. D., Barron, D. G., and Shimizu, T. (2018). Simulated viral infection in early-life alters brain morphology, activity and behavior in zebra finches (Taeniopygia guttata). Physiol. Behav. 196, 36-46. doi: 10.1016/j.physbeh.2018.08.004

Van Schaik, C. P., and Deaner, R. O. (2003). "Life history and cognitive evolution in primates," in Animal Social Complexity, eds F. B. M. De Waal and P. L. Tyack (Cambridge, MA: Harvard University Press).
Vas, Z., Lefebvre, L., Johnson, K. P., Reiczigel, J., and Rózsa, L. (2011). Clever birds are lousy: Co-variation between avian innovation and the taxonomic richness of their amblyceran lice. Int. J. Parasit. 41, 1295-1300. doi: 10.1016/j.ijpara.2011. 07.011

Villa, S. M., Goodman, G. B., Ruff, J. S., and Clayton, D. H. (2016). Does allopreening control avian ectoparasites? Biol. Lett. 12:20160362. doi: 10.1098/ rsbl.2016.0362

Weldon, P. J., Carroll, J. F., Kramer, M., Bedoukian, R. H., Coleman, R. E., and Bernier, U. R. (2011). Anointing chemicals and hematophagous arthropods: responses by ticks and mosquitoes to citrus (Rutaceae) peel exudates and monoterpene components. J. Chem. Ecol. 37, 348-359. doi: 10.1007/s10886011-9922-7

Whiten, A., and Byrne, R. (1997). Machiavellian Intelligence II: Extensions and Evaluations. 2nd Edn. Cambridge: Cambridge University Press.

Wilson, D. S., Coleman, K., Clark, A. B., and Biederman, L. (1993). Shy-bold continuum in pumpkinseed sunfish (Lepomis gibbosus): an ecological study of a psychological trait. J. Comp. Psychol. 107, 250-260. doi: 10.1037/0735-7036. 107.3.250

Zhang, Y., Lu, H., and Bargmann, C. I. (2005). Pathogenic bacteria induce aversive olfactory learning in Caenorhabditis elegans. Nature 438:179. doi: 10.1038/ nature 04216

Conflict of Interest: The authors declare that the research was conducted in the absence of any commercial or financial relationships that could be construed as a potential conflict of interest.

Copyright (c) 2020 Ducatez, Lefebvre, Sayol, Audet and Sol. This is an open-access article distributed under the terms of the Creative Commons Attribution License (CC BY). The use, distribution or reproduction in other forums is permitted, provided the original author(s) and the copyright owner(s) are credited and that the original publication in this journal is cited, in accordance with accepted academic practice. No use, distribution or reproduction is permitted which does not comply with these terms. 